\title{
Idiopathic retroperitoneal fibrosis - is serum alkaline phosphatase a marker of disease activity?
}

\author{
I.G. Barrison, J.G. Walker, C. Jones and M.E. Snell \\ Gastroenterology and Urology Units, St Mary's Hospital, Praed Street, London W2 INY, UK.
}

\begin{abstract}
Summary: Two patients are presented in whom extensive investigations were carried out to determine the cause of a raised serum alkaline phosphatase. Idiopathic retroperitoneal fibrosis was diagnosed in both cases and the serum alkaline phosphatase returned to normal following treatment with corticosteroids and coincident with resolution of the patients' symptoms.
\end{abstract}

\section{Introduction}

Idiopathic retroperitoneal fibrosis (RPF) is an uncommon condition ${ }^{1,2}$ which may be present in patients initially referred to a gastroenterologist with abdominal symptoms. Two patients are described in whom extensive investigations were carried out to determine the cause of a raised serum alkaline phosphatase, apparently of hepatic origin, before the diagnosis of RPF was confirmed.

\section{Case reports}

Case 1

A 51 year old previously fit woman presented with a 2-month history of continuous central abdominal pain radiating to the left hypochondrium. Clinical examination was unremarkable.

Initial investigations were as follows: haemoglobin $11.4 \mathrm{~g} / \mathrm{dl}$, erythrocyte sedimentation rate (ESR) $63 \mathrm{~mm}$ in the first hour (Westergren), serum alkaline phosphatase $213 \mathrm{U} / 1$ (normal range 50$130 \mathrm{U} / \mathrm{l})$, the remainder of the liver function tests were normal. Chest X-ray, gastroscopy, upper abdominal ultrasound, intravenous urogram (IVU), barium enema, isotope bone scan, barium followthrough, endoscopic retrograde cholangiopancreatography (ERCP) and liver biopsy were within normal limits. Computed tomographic (CT) scan of the abdomen suggested the presence of para-aortic lymphadenopathy. The abdominal pain

Correspondence: I.G. Barrison, B.Sc., M.R.C.P., Gastroenterology Unit, St Mary's Hospital, Praed Street, London W2 1NY, UK.

Accepted: 29 September 1987 proved to be intractable and a laparotomy was carried out 3 months after the first presentation. No abnormality was detected. The pattern of the ESR and serum alkaline phosphatase subsequently is shown in Figure 1(a). Repeat CT scan in December 1984 showed a hydronephrosis of the left kidney and a further IVU demonstrated deviation and constriction of the ureter at the pelvic brim.

The patient refused retroperitoneal biopsy. Retroperitoneal fibrosis was diagnosed on clinical grounds and prednisone $40 \mathrm{mg}$ /day was commenced. There was subsequently a rapid decline in the ESR and serum alkaline phosphatase coincident with disappearance of her symptoms. The patient remains well and asymptomatic 2 years later, on prednisolone $5 \mathrm{mg} /$ day. Electrophoresis of the alkaline phosphatase on three separate occasions showed this to be a liver isoenzyme.

\section{Case 2}

A 56 year old man with previously treated pulmonary tuberculosis gave a 3-year history of central abdominal pain radiating to the back. General examination was normal apart from enlargement of the prostate gland.

Investigations were as follows: haemoglobin $11.1 \mathrm{~g} / \mathrm{dl}$, ESR $150 \mathrm{~mm}$ in the first hour, serum alkaline phosphatase $660 \mathrm{U} / 1$ (liver isoenzyme), serum albumin $32 \mathrm{~g} / \mathrm{l}$. The remainder of the liver and renal function tests were normal. Previous upper gastrointestinal endoscopy, barium meal and follow-through, barium enema, and liver and gall bladder ultrasound were normal. An IVU showed bilateral hydrophrosis with dilatation of the

(C) The Fellowship of Postgraduate Medicine, 1988 


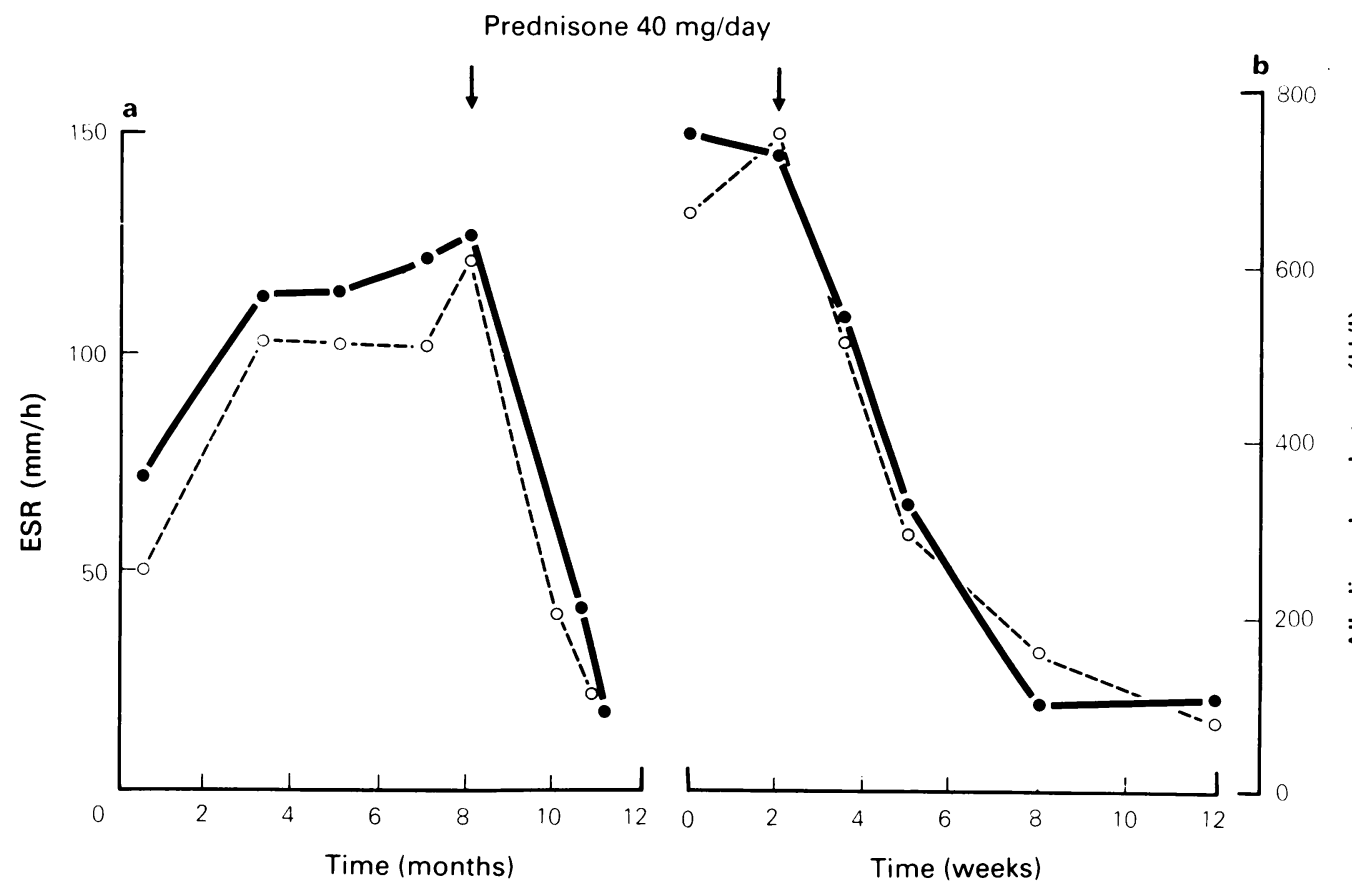

Figure 1 Pattern of serum alkaline phosphatase and ESR and response to steroid therapy in (a) Case 1 and (b) Case 2. -

abdominal parts of the ureters (Figure 2). Repeat ultrasound of the liver and gall bladder was normal and liver biopsy showed a patchy mild chronic inflammatory infiltrate around portal tracts with normal bile ducts.

Laparotomy was carried out and showed white fibrous tissue around the pelvic brim, histological examination of which demonstrated vascular fibrous connective tissue with areas of haemorrhage and small foci of inflammation particularly around the small blood vessels. These changes were consistent with the diagnosis of idiopathic retroperitoneal fibrosis.

Treatment with prednisone $40 \mathrm{mg} /$ day resulted in rapid resolution of symptoms and decline of the serum alkaline phosphatase and ESR as shown in Figure 1(b). The patient remains well and asymptomatic one year later on prednisone $5 \mathrm{mg} /$ day.

\section{Discussion}

The diagnosis of idiopathic RPF was made after numerous investigations of the liver and biliary tract in both these patients, in whom repeated isoenzyme studies suggested that the raised serum alkaline phosphatase was of hepatic origin. Eventually the diagnosis of RPF was made, in one case by laparotomy and biopsy and in the other by CT scan. RPF may rarely directly involve the common bile duct, ${ }^{3}$ and has been described in association with sclerosing cholangitis. ${ }^{4}$ There was no evidence of either of these conditions in our two cases. A raised serum alkaline phosphatase of apparent hepatic origin may be found in up to a third of patients with polymyalgia rheumatica, giant cell arteritis, ${ }^{5}$ rheumatoid arthritis, ${ }^{6}$ and ankylosing spondylitis, ${ }^{7}$ all 'vasculitic' conditions like RPF. Despite an extensive literature review, no previous reports of an association between a raised hepatic alkaline phosphatase and RPF have been found.

Lepor and Walsh ${ }^{1}$ reviewed 70 cases of idiopathic RPF of whom $66(94 \%)$ had an elevated ESR. A raised serum alkaline phosphatase was not mentioned.

Recently a very similar enzyme to hepatic alkaline phosphatase has been identified in the capillaries and arterioles within portal tracts. ${ }^{8}$ This enzyme may be present in other vessels damaged by the arteritis of retroperitoneal fibrosis. The rapid decline of the alkaline phosphatase in both these patients in parallel with the ESR indicates that it probably is a marker of disease activity in these cases of RPF and this diagnosis should clearly be considered in patients with vague abdominal pain, a high ESR and a raised alkaline phosphatase for which no obvious cause is found. 


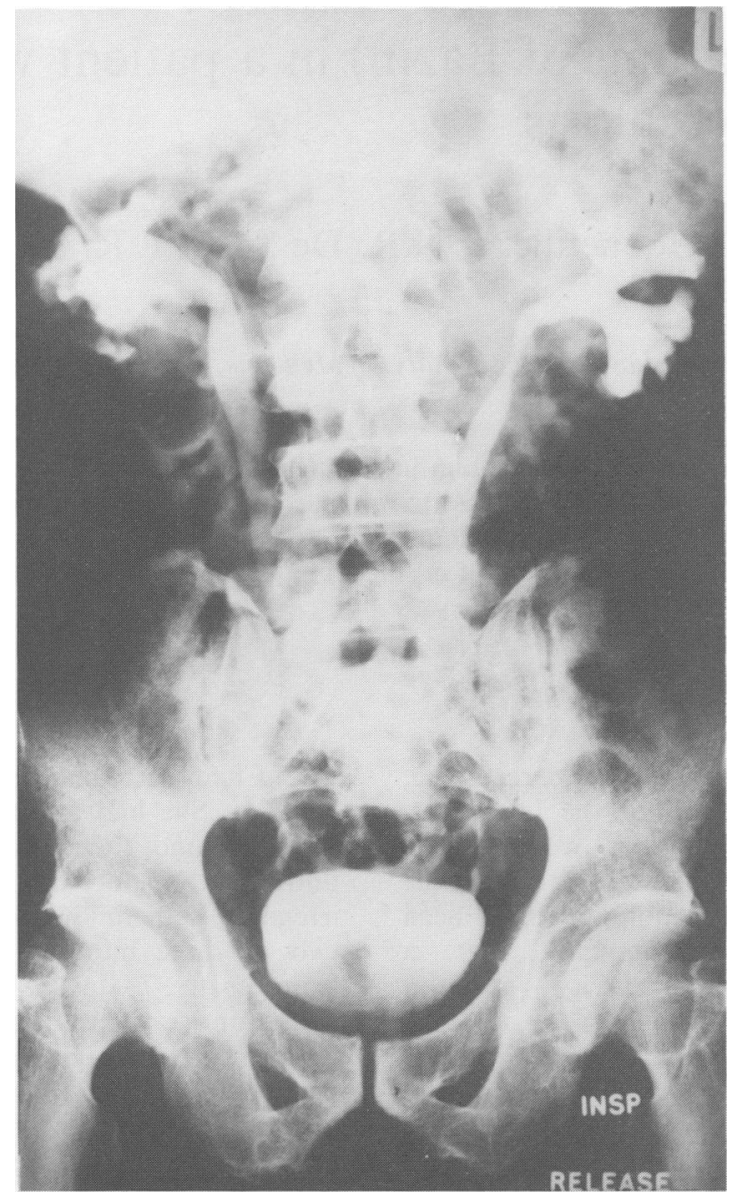

Figure 2 IVP showing bilateral hydronephrosis with dilatation of the abdominal parts of the ureters (Case 2).

\section{References}

1. Lepor, H. \& Walsh, P.C. Idiopathic retroperitoneal fibrosis. J Urol 1979, 122: 1-6.

2. Anon. Idiopathic retroperitoneal fibrosis. $\mathrm{Br} \mathrm{Med} J$ 1981, 1: 1343.

3. Renner, I.G., Ponto, G.C., Savage, W.T. \& Bosewell, W.D. Idiopathic retroperitoneal fibrosis producing common bile duct and pancreatic duct obstruction. Gastroenterology 1980, 79: 348-351.

4. Alpert, L.T. \& Jindrak, K. Idiopathic retroperitoneal fibrosis and sclerosing cholangitis with a reticulum cell carcinoma. Gastroenterology 1971, 62: 111-114.

5. Sheehan, N.J. Alkaline phosphatase and serum $\gamma$ glutamyl transferase in polymyalgia rheumatica and giant cell arteritis. Ann Rheum Dis 1985, 44: 644-645.
6. Spooner, R.J., Smith, D.H., Bedford, D. \& Beck, P.R. Serum gamma glutamyl transferase and alkaline phosphatase in rheumatoid arthritis. $J$ Clin Pathol 1982, 35: 638-641.

7. Sheehan, N.J., Slavin, B.M., Kind, P.R.N. \& Mathews, J.A. Increased serum alkaline phosphatase activity in ankylosing spondylitis. Ann Rheum Dis 1983, 42: 563565.

8. Hatoff, D.E., Toyata, H., Wang, C., Miller, A.L., Takeyam, M. \& Miyai, K. Rat liver alkaline phosphatase - evidence that hepatocyte and portal triad enzymes differ. Dig Dis Sci 1985, 30: 564-572. 